\title{
Control and Surveillance in Work Practice: Cultivating Paradox in 'New 'Modes of Organizing
}

By:

François-Xavier de Vaujany (Université Paris Dauphine-PSL, DRM, France)

Aurélie Leclercq-Vandelannoitte (CNRS, LEM, IESEG School of Management, Univ. Lille, UMR 9221, France)

lain Munro (Newcastle University Business School, UK)

Yesh Nama (RMIT University, Australia)

Robin Holt (Copenhagen Business School, Denmark)

\section{Abstract}

The new world of work is being characterized by the emergence of what are, apparently, increasingly autonomous ways of working and living. Mobile work, coworking, flex office, platform-based entrepreneurship, virtual collaborations, Do It Yourself (DIT), remote work, digital nomads, among other trends, epitomize ways of organizing work practice that purportedly align productivity with freedom. But most ethnographical research already reveals many paradoxical experiences associated with these new practices and processes. Indeed, it appears that with autonomy comes surveillance and control, to a point where, as Foucault observed way back, subjectivity and subject become synonyms, and the current pandemic both strengthens and makes visible this situation. In this introduction to the special issue we make a foray into this situation, using four open and related themes developed in the five papers we selected: managerial control and technology; surveillance and platform capitalism; time and space; and new organizational forms and autonomy. Paradoxical movements are identified for each of them, before we 
conclude by reflecting on a grounding paradox which appears at the centre of this special issue and the themes it covers.

\section{Keywords}

control systems, new forms of organizing, new ways of working, organizational control, remote work, surveillance capitalism, surveillance

Our society is not of spectacle, but of surveillance ... (Foucault, 1977, p. 217)

\section{Introduction}

The shift from office-based work to telework, from direct supervision to distance management, from face-to-face to technology-mediated communication, from co-located teams to various forms of virtual and physical collaboration, from pre-defined work time to 'flex time '(Bailey \& Kurland, 2002; Brocklehurst, 2001; Gonsalves, 2020; Hafermalz \& Riemer, 2020; Kurland \& Egan, 1999; Sewell \& Taskin, 2015; Tietze \& Musson, 2005; Wilson, O'Leary, Metiu, \& Jett, 2008), in particular during the Covid-19 crisis (Leonardi, 2021), raises many paradoxical organizational challenges, not least a continuing and indeed tightening association of autonomy with surveillance and control, along with the organizational question of understanding, anticipating and controlling what is beyond the sensory purview of managerial practice (Dambrin, 2004; Halford, 2005; Sewell, 2012). Though in response surveillance is becoming mobile, flexible, pervasive and unbounded (Bauman \& Lyon, 2013; Hansen \& Weiskopf, 2021), and so in turn control is becoming more a capillary than an overt force, organization is being mediated by technological processes whose incessant spread is accompanied by an unruliness that upsets the hitherto unchallenged coupling of work practice and managerial oversight. 
It was the emergence of new ways of working (Aroles, Mitev, \& de Vaujany, 2019, p. 286), as 'a wide range of practices placed on a continuum of work flexibilization and diversification, from remote work to collaborative entrepreneurship and digital nomadism', often described as expression of emancipation, autonomy and self-determination, coupled, paradoxically, to control and surveil- lance, that encouraged us to envisage a special issue on the theme. We called for insightful pieces for management and organization studies to enrich our understanding of surveillance and control in the 'new 'worlds of work, organization and management. While the concepts of control and surveillance are very closely related, the intimate links between them deserve more systematic investigation along with new modes of organizing and their implications for the autonomy of the actors involved.

Control and surveillance practices are of long-standing concern to organization studies, indeed, given their association with control mechanisms (Best, 2010; Clegg \& Dunkerley, 1980), they might be said to constitute the modern organizational condition (Lyon, 2002; see also Giddens, 1985). Control can even appear historically as the 'raison d'être 'of organizations as formal structures and ways of organizing (de Vaujany, 2010; Kieser, 1989). Emerging information technologies have increased the scope and reach of surveillance in contemporary societies to such a degree that it has almost become an a priori condition. The disciplinary, state-sanctioned actions taken in response to tackling the Covid-19 pandemic provide visible expression of the intense scrutiny and monitoring of citizens which is now possible. States and private corporations can use digital traces to monitor their customers, employees and citizens, for diverse aims including surveilling their activities (Leclercq-Vandelannoitte \& Aroles, 2020), capturing their attention and modifying their behaviour (Flyverbom, Deibert, \& Matten, 2019; Srnicek, 2017; Zuboff, 2019). They augur a new organization of our freedoms (Deleuze, 1992) which have been 
paving the way to horizontal modes of sense-making and surveillance (de Vaujany \& Mitev, 2017).

For instance, some of the new healthcare surveillance technologies (apps such as Covid Safe, TraceTogether, etc.) track people's digital (and physical) footprints by means of information provided directly or indirectly by people themselves. Although the actual practices of individuals are often at odds with claims valuing privacy (cf. the well-known 'privacy paradox', Pavlou, 2011; and the emergence of 'behavioral visibility 'as a new paradigm, Leonardi \& Treem, 2020), and despite the obvious health benefits to virus trackand-trace systems, many people are concerned about 'surveillance creep', i.e. surveillance developed for a limited purpose, such as fighting a pandemic, subsequently being used in more pervasive and enduring manner (Calvo, Deterding, \& Ryan, 2020; Rowe, Ngwenyama, \& Richet, 2020) and accepted as the 'new normal '(Leclercq- Vandelannoitte \& Aroles, 2020). This is all the more problematic given that 'such intense scrutiny not only extracts information about the activities of individuals, it also goes a long way to shaping their subjectivity as they come to see themselves in the ways they are defined through surveillance '(Sewell, 1998, pp. 403-404).

The Covid-19 pandemic reveals how digitization, organizational fragmentation and mass surveillance are shattering the presumed dualistic order of controller and controlled. Surveillance and control is something far more immanent to and embedded within our everyday social interactions. In this context, the purpose of this special issue is to rethink control and surveillance by developing a more materialized, spatialized, embodied and temporalized view in relation to new work practices (Aroles et al., 2019; Dale, 2005; Hardy \& Thomas, 2015; de Vaujany \& Aroles, 2019). Questions of space, time, corporeity, embodiment, visuality and materiality are at the heart of the theories, concepts and interpretations provided in our special issue, which critically discusses the experiences of 
control and surveillance in the new world of work, organization and management, and their ontological underpinnings.

Our special issue comprises five contributions all of which resonate with ongoing debates about control, surveillance and new modes of organizing work: issues of exile and remote working (Hafermalz, 2021), collaboration and communities (Resch, Hoyer, \& Steyaert, 2021), gender and sexual identity in the new world of work (Burchiellaro, 2021), open office design and governmentality (Picard, Durocher, \& Gendron, 2021) and algorithmic surveillance (Newlands, 2021). In such a world, organizing appears more paradoxical than ever, particularly in its demands for, on the one hand, greater autonomy, transparency and collaboration, and on the other, greater control, opacity and competition. Thus, if workers are given more and more autonomy at work and in their lives (e.g. with remote work and telework), the spatial configuration of their work at home, or at the coworking space close to their home, and the digital tools they use while in mobility, along with the platforms increasingly used to connect workers, all paradoxically link with increased surveil- lance using mobile surveillance technologies, algorithmic controls of work allocation, and intensified performance metrics: precarity enhances surveillance and control (see Hafermalz, 2021 and Newlands, 2021 in this issue). In this vein, if the new world of work is often presented as a worker- developed response to changing economic conditions, such that the figure of these new workers is often 'imbued with self-determination '(de Peuter, Cohen, \& Saraco, 2017, p. 693), their autonomy of choice also comes with new constraints and neoliberal modes of self-discipline (all the more implying that autonomy, flexibility and networks are often embraced at the expense of stable employment and social protection see de Peuter et al., 2017, p. 689; Gandini, 2015).

For example, the search for freedom and more autonomous ways of working are captured by new processes exploiting our everyday movements and interactions (e.g. with the sale of data of geolocation, a full availability and visibility of freelancers to the platform hosting 
them, or the opening of numerous third-places such as coffees with good Wi-Fi in the middle of connective hubs), which had previously been little more than mundane activities, quickly forgotten. Our mate- rial walks, gestures, speeches and the places we cross are riven with an increasingly organized immaterial space that marks and nudges us, keeping us on the grid. The reasoning is that the density and spread of surveillance and control have 'economic value 'which is becoming by itself more and more relational (as it is related massively to other data and other behaviours 're-presented 'by them). Yet in turn the value is only sustained if more frequent and intense experiences of autonomy are made possible. In this way the paradox of autonomy and control that is mapped out in this special issue engages both with 'freedom's refusal to submit 'to power (Foucault, 1982, p. 790), while acknowledging 'Foucault's account of a mutually intensifying and productive relationship between power and freedom '(Raffnsøe, Mennicken, \& Miller, 2019, p. 162). Organization studies are suggesting surveillance and control do not belong in one class, and autonomy in another. In breaking open the traditional opposition between classes, they reveal the disciplinary nature of our thinking using fixed categories and concepts (the 'oppressed', 'the free'), and believing them to actually exist. If worker mobility generates greater restriction of movement, its paradoxical resonance might prompt us to think more critically about the conceptual architecture of organization studies (Quine, 1976, pp. 6-7). As well as constituting a fertile ground for critical study, the experienced reality of surveillance and control, and the intimacy with autonomy, reveals the concealing nature of categories and concepts; the singularities of life outwit the generalities of grammar. Our goal here is to make sense of the beginnings, underlying dynamics and intensification of these elusive, seemingly paradoxical conditions. We do so by introducing four open and related themes developed in the five papers selected for this special issue: managerial control and technology; surveillance and platform capitalism; time and space; and new organizational forms and autonomy. Paradoxical movements will be identified for each of 
them, before concluding with a grounding paradox which appears at the centre of this special issue and the themes it covers.

Managerial Control and Technology

Since the inception of management, the apparent tension between surveillance and control on the one hand (e.g. the proto managers of the early industrial revolution were known as 'overseers') and autonomy on the other (i.e. the freedom to think and act in accord with the full range of one's human potential) has always been central in managerial and organizing processes. To manage was to take part in a struggle over the organization of the motive power of labour and machinery. Control, which has long appeared a key function of managers (Marglin, 1976; Mintzberg, 1983) and a 'dominant part of their job ' (Alvesson \& Kärreman, 2004, p. 424), and indeed constitutive of managerial identity (Sveningsson \& Alvesson, 2003; Wiesenfeld, Ragurham, \& Garud, 1999), was defined as 'the ability of capitalists and / managers to obtain desired work behavior from workers ' (Edwards, 1979, p. 17). Control and predictability are considered an integral aspect of organizational behaviour (Clegg \& Dunkerley, 1980), helping to ensure the setting and reaching of objectives (Braverman, 1974; Flamholtz, 1996). To that end, managerial control includes all the (formal and informal) actions exerted by managers to direct or influence their employees 'conduct, in a 'balanced 'manner entailing both motivating incentives and effective sanctions, so that they result in behaviour consistent with organizational aspirations, rules and objectives (Flamholtz, 1996).

The managerial concern for balance first appears explicitly with what Edwards calls the small business of 19th-century Europe and the United States, whose entrepreneurial actions 'combined both incentives and sanctions in an idiosyncratic and unsystematic mix. There was little structure to the way power was exercised and workers were often treated arbitrarily '(Edwards, 1979, p. 19). In short, control was based on directly embodied and hierarchical supervision and surveillance. Towards the end of the 19th century, the 
emerging larger corporate forms were adopting more structural forms of technical and bureaucratic control (Clegg \& Dunkerley, 1980; Edwards, 1979), and disciplinary power (Deetz, 1992). Technical controls, augmented by Taylorism (Sewell, 1998), were consciously contrived controls embedded in the physical structure and the space of the labour process, whereas bureaucratic controls were part of the social structure or relations of the work- place (Edwards, 1979, pp. 20-21). With the implementation of both forms, relationships between superiors and subordinates were governed by non-negotiable procedures and mechanical rhythms, all of which was directed toward a locus of balance and equilibrium (de Vaujany \& Mitev, 2017; Kaye, 2014; Kline, 2006; Robb, 1984; Umpleby, 2005). Managerial control was understood as a homeostatic process aiming to integrate and harmonize the multiple (but typically linearly conceived) forces in play, and surveillance remains here a tool for enacting such. So, accompanying the cultivation of predictable, linear relationships between things, subjects, organizational units, divisions and markets is an orthogonal language of verticals and horizontals, of chains of command and line management, and of overviews, corrections and reviews. A language that has been abetted by accounting control techniques such as book keeping that have instituted a logic of balance and control into organizational procedures (Quattrone, 2019), fostering the emergence of a professional class of experts ('managers') to whom specific control and surveillance roles, such as auditing on behalf of investors, could be assigned (Burnham, 1941).

In this development, managerial control and surveillance has been abetted by technology. Though touted as a tool - a kind of prosthetic extension that furthers the managerial reach, allow- ing what was far to come closer, and what was complex to be made clearer technology has always acted as a mediating force that conditions, and indeed governs, the organizational forms through which managerial control and surveillance practices cohere. For example, the idea of machine- supported, autonomous decision-making among senior 
strategists - a kind of centralizing electronic brain of humans and computers that would strengthen and extend the adaptive potential of organizations (Heims, 1991) - gave rise to the institutionalization of 'communication 'as an all- pervasive, digitized 'semiosis '(as a production of meaning) of fluid flows of information, direction, review and correction (de Vaujany \& Mitev, 2017). The computers still worked with files, index cards, steel-framed curtain wall building construction, and elevators, for example, all coalesce in the materialized possibility for enhancing administratively tight, visible and clear forms of control and surveillance through which autonomy became a form of willing compliance with, and expression of, bureaucratic norms of efficiency, meritocracy and predictability. The job at hand being to explicitly acknowledge and reconcile differing ambitions, activities, motivations, intentionality, situational distinctions, contingencies and practices (Ahrens \& Mollona, 2007, pp. 310-11), to thereby ensure a singular organizational direction (Courpasson, 2000; Monteiro, 2018).

It was with the tightening of this technological impress, however, that overt managerial control and surveillance also, paradoxically, began to loosen. Technology made possible an increasingly networked society and the gradual deconstruction of firms being governed by the visible hand of overt management (albeit gradually, via looser organizational forms such as outsourcing, freelancing, project management, joint ventures, global logistics, autonomous groups, management by objectives, self-organized teams and, later, lean management etc.). Control and surveillance ceased to have a defined origin, indeed they ceased to be defined by distinct practices, and instead became decentred phenomena woven into a myriad of agencies assembled and de-assembled through collective activities themselves in a space which was continually unfolding, riven with multiple interests that are as political as they are commercial (Ball, 2005). Foucauldian organization studies have previously argued that while disciplinary power remains very much in evidence in modern organi- zations, the control and surveillance has become increasingly free floating and no 
longer limited by material architecture (the panopticon) or direct supervision (e.g. see Ball, 2005; Brivot \& Gendron, 2011; Leclercq-Vandelannoitte, Isaac, \& Kalika, 2014; Munro, 2000, 2012; Raffnsøe et al., 2019). The present special issue shows how new platform organizations exploit algorithms and workers 'anxieties over their human capital in the decentralized control of increasingly precarious workers (Hafermalz, 2021 and Newlands, 2021, in this issue). Control and surveillance are less intrusive and visible, and much more assimilated and incorporated into the objects of our everyday life - our computers, our phones, cars, buildings, streets, clothing, and so on. Our smartphones, our digital payment tools (more invisible than ever and more and more related to the idiosyncrasies of our biological body), our gestures in public spaces covered by unobtrusive cameras, feed a global infrastructure of surveillance and control that forms less an array of defined conditions than a medial a priori of organizing (Beyes, Holt, \& Pias, 2019, p. 505). And so now, in so many aspects of work life, with social media, online meetings, platformbased interactions, events in coworking spaces, Bring Your Own Device (BYOD) programs, there is no presumption of a homeostatic balance or transcendent organizational synthesis fixed on well- defined goals. Strategy, in its classical guise, as a deliberate, programmatic process, has become impossible. At one and the same time, management attempts to enforce increasingly tight and restrictive forms of organizational control and surveillance, while being subjected, along with everything else, to ungovernable technologies. Through such conditioning, organizations prefer to employ strategies of lobbying, public relations and outright denial to address the significant social, financial and environmental externalities associated with business (MacKay \& Munro, 2012).

\section{Surveillance and Platform Capitalism}


This technological transformation and broader institutional becoming are conceptualized by Zuboff (2015, p. 75) as 'surveillance capitalism'. Zuboff emphasizes a transition in work organization from the division of labour to a 'division of learning 'which has found workplaces being organized by access codes and restricted interfaces rather than production lines, and which has resulted in a welter of jobs being given over to machines. Machinery is more efficient at gathering, storing, processing and distributing information; indeed, its mediating presence determines what counts as information. And as Zuboff (2019) observes, with the irresistible spread of the Internet, clouds, trackers, sensors and mobile media devices, this division of learning extends well beyond the workplace:

The dilemmas of knowledge, authority, and power have burst through the walls of the workplace to overwhelm our daily lives. As people, processes, and things are reinvented as information, the division of learning in society becomes the ascendant principle of social ordering in our time. (Zuboff, 2019, p. 183)

In such a time-space, work and leisure are everywhere and nowhere, they are not grounded in a specific place and time any more. And all our movements, speeches, acts of consumption become meaningful. They leave numerous digital traces likely to be combined to produce interpretations, decisions, propositions. Surveillance becomes part of a daily routine guaranteed by our own self-control.

This semiosis is the opposite of that prevalent till the late Middle Ages, a period at which 'object-images 'and heavy materialities were at the heart of sense-making processes (Baschet, 2008; de Vaujany \& Vaast, 2016). At that time, something meaningful was always somewhere, encountered during a specific time (a ritual) and extensively material (see the example of the laby- rinth in Chartres Cathedral which makes sense only at the entrance of the Cathedral and encoun- tered as part of the liturgy). Gradually over the modern period, semiosis became much more grounded into 'screen-images', i.e. signs performed through a transparent medium (de Vaujany \& Vaast, 2016). The time and space 
of the process of sense-making were not expected to be meaning- ful per se. Reading this article on a laptop, a tablet or on printed paper will not modify its expected meaning. And the matter and shape of our mediations became meaningless, only something borrowed ('surfaces d'emprunt'). Our mood and immediate context can change our reading of this article, but the way we make the text happen (with the surface of paper, a tablet, a laptop) is not expected to be part of the initial message. With the birth of screen-images, sensemaking becomes thus more than ever an autonomous temporalization and materialization (Barker, 2012, 2018).

Screen-images also have a depth. In some respects, digital semiosis is thus primarily a transparent process presented by search engines and the screens of our mobile devices. But in other respects, digital semiosis has been obscured by the user-friendly interface which tells us nothing of the complex algorithms operating behind it (Alaimo \& Kallinikos, 2020), where 'digital technologies are now shaping physical reality '(Baskerville, Myers, \& Yoo, 2020, p. 509). This transparent and highly intuitive medium in our hands performs the message as much as it conveys it. Control is thus more invisible and harder to question in our screen-images based world. We are too close to the screen to question it. And this 'cave 'is too flat to enable us to look back or let us go outside.

The organizational form of surveillance capitalism is the platform (Kolb, Dery, Huysman, \& Metiu, 2020). Platforms are digital mediators that foster transactions (i.e. an instance of buying or selling something) between different parties, using data on these interactions to extract profits. Their core operations are based on data gathering, analysis and distribution that constitute a new form of exchange, which in turn augurs a new form of low wage, disenfranchised, precarious labour (Srnicek, 2017). Their operative strategy is a dual approach of infecting the wider Internet, and preparing the Internet for infection, so as Helmond (2015) observes, platforms offer frame- works others can use to enhance the connectivity and presence of their websites, apps and data, and at the same time, they 
shape data into forms that can be absorbed by the logic of their own economic models. In contrast to the relatively open architectures, which helped create the Internet, the new platforms serve to reorganize online communication, gaming and trade as purely surveilled and commodified interactions.

While the workers may be decentralized, the mechanism for their coordination and the extraction of profits - i.e. the 'app - 'is centralized. Concerns have been raised that platform companies such as Uber, Airbnb, Facebook, Alibaba, Tencent and Amazon, among others, have led to a massive centralization of the data ' -big data - 'being used to manipulate customers and voters (Vaidhyanathan, 2018; Zakir, Seymour, \& Berg, 2015), exploiting what Zuboff (2019) calls, with a nod to Marx, the 'behavioural surplus 'generated through the analysis of user interactions and sale of attention space. Corporations like Google have been pursuing strategic investments with a technologically mediated focus on building revenue stream, despite originally having identified themselves with broader socially motivated missions (in Google's case, espousing to organize the world's knowledge). While Google's strategy is commercially effective, having attained its legitimacy through the singular focus on developing a technical prowess in algorithmic monitoring and prediction of preference patterns, it has eclipsed a broader social, environmental and civic sensibility. The business model of Google, Facebook and many other companies involves a systematic transgression of individual privacy and the mediation and/or manipulation of consumer choices - a feature which is common to most social media platforms and gig economy corporations. The disciplinary and control practice of monitoring, aggregating and sorting data is termed dataveillance (Raley, 2013, p. 124). Platforms, however, are not simply stacks of digital technology. Steinberg (2019) discusses them pre-dating digital computing by a century or so, arising as they did as a mediation device to manage activity, thought and relationships in such a way that the thinking and activity encouraged by scientific management would then percolate through to 
consumer and more broadly social behaviour; for Steinberg (2019), it is technology as practice, pushed through toward the social body long before the rise of digital computers, for example the car chassis (or platform) cast within Toyota's much-touted single metal die operation which formed the origins of lean thinking, demand-led production and global supply chains.

682 Organization Studies 42(5)

So questions must be asked about the apparent contradiction between autonomy and surveil- lance and control that these technological and societal transformations are indicative of - is it narrowly focused on the particular kind of algorithmic technologies being developed (e.g. see Zuboff, 2019), or is it grounded in a more general historical movement concerning the evolution of the capitalist mode of production (e.g. see,Mozorov, 2019; Srnicek, 2017)? And what are the implications for understanding tactics of resistance to these new technologies given their emergence from a historical of technological transformation (Hardt \& Negri, 2009; Marx, 1976)? New tactics of resistance are taking many forms including exploiting inconsistencies between the virtual and material worlds being presented in apps (see Newlands, 2021, this issue), voluntary exile by refus- ing to participate in the 'human capital 'game (Hafermalz, 2021, in this issue), using techniques of surveillance obfuscation (Brunton \& Nissenbaum, 2015), and exposing corporate corruption using deterritorialized networks (Munro, 2016).

Relatively little research has been conducted into the tactics of resistance developed by workers to exert their autonomy in the face of these new systems of control; however, a number of papers in this special issue are devoted to precisely this concern. Gemma Newlands (2021, this issue) investigates the effects of algorithmic surveillance in the food delivery industry which uses a mix of mobile technologies of surveillance with both consumer and management oversight to supplement the technological systems of control. 
The analysis shows how 'carto- graphic dissonance 'emerges where mapping technologies do not adequately account for the material realities of lived space and the obstacles to human movement in space. The paper identifies an 'epistemological gap ' between the lived material reality of the workers and their movement in space and its virtual representation by systems of digital surveillance, where this gap gives rise to opportunities for workers to develop tactics of resistance to the techniques of algorithmic surveillance. Individualist and collectivist tactics of resistance to algorithmic surveillance are identified which detail how workers developed tactics including swapping devices, temporarily switching them off, coordinating collective protests and other ways to confound systems of algorithmic control.

Another tactic of resistance to platform capitalism and new systems of algorithmic control is advocated by Hafermalz (2021, this issue), who explains how the new systems of control are far more distributed and decentralized than the traditional panoptic metaphor would suggest, and where fear of exile now plays a prominent role in control. According to Hafermalz, the fear of exile, which develops from being away from centres of power, leads to new political dynamics grounded in an entrepreneurial logic in which employees vie for 'competitive exposure 'and 'existential recognition', which are built into modern digital technologies to control workers. Hafermalz develops an insightful contribution to understanding how modern forms of digital technology com- bine with a neoliberal ideology to develop techniques of 'government through freedom', based upon an entrepreneurial logic in a market for recognition. Hafermalz observes a profound ambivalence of exile as a tactic of resistance since it is both a tactic of control as well as being fertile ter- rain for the evolution of critical perspectives and new forms of protest. The existential aspects of resistant identities are also investigated in Burchiellaro's (2021, this issue) account of 'queering control 'which shows that although there has been progress in the adoption of LGBT-friendly working practices in contemporary workplaces, this inclusion 
of queer identities is moderated both by bureaucratic controls and capitalist imperatives. This paper maps out the limits of the queering of control, explaining how 'forms of LGBTfriendly control are particularly taxing for employees who experience and/or perform their gender/sexuality beyond normative understandings '(Burchiellaro, this issue, p. 20). The practices of control and resistance detailed in these articles of our special issue show how autonomy itself is becoming a new locus of exploitation in these new work practices.

\section{Time and Space}

Emphasizing the platform reveals control and surveillance being increasingly enacted through sensory perception and affect. The sensory orders often receive short shrift in studies of control and surveillance. Zuboff (2015, 2019), for example, despite her entire thesis being built on the extraction and exploitation of users 'experience, gives us very little analysis of what such experience actually is, and so how it is that the experience itself - its affective, emotional and sensual pull - is what is being consumed (Friis Nielsen, 2021). As Reckwitz (2016) observes, however, organization is both a social and a sensory order, and surveillance and control are increasingly occurring at this capillary level. For Idhe (2009, pp. 33,43 ) this felt, technological, bodily grounding of work experience finds surveillance and control becoming increasingly concealed and insinuated into everyday social interactions. As such, they become mediations of experience rather than limits or obstructions to it (Ihde, 2009, p. 43). This entails a shift of phenomenological concern towards a sensory attunement to how digital technologies are actualized affectively through embodied interactions (Hansen, 2006; see also Sage, Vitry, \& Dainty, 2020). Organization might be read atmospherically, as a continual spatial consolidation and projection of forms whose cohesiveness (integrity) and potential (permeability) are mediated technologically (De Molli, Mengis, \& van Marrewijk, 2020; Jørgensen \& Holt, 2019). Resch et al. (2021) find this affectively mediating force appearing in communal fantasies of purpose, growth 
and belonging, all of which, in their different ways, evoke a sense of autonomy through control, and control through autonomy. Couched in the language and concepts of psychoanalysis, the fantastical is materially rather than discursively grounded. The sensory ordering of surveillance and control has been a long-standing concern of spatial theory and studies (Beyes \& Holt, 2020; Dale \& Burrell, 2008; Delbridge \& Sallaz, 2015; de Vaujany \& Mitev, 2017; Munro \& Jordan 2013). In the context of the 2020 Covid19 pandemic, it has become irresistible. Newly developed systems and their networked, connected methods of surveil- lance (through applications tracking contacts and movement) are being deployed everywhere in the world, to reorganize freedoms in the wake of their having been suspended by scientifically sanc- tioned, sovereign declarations of exception (Leclercq-Vandelannoitte \& Aroles, 2020; Rowe et al., 2020). Thus, making particularly salient the autonomy vs. control debate, notably in an assemblage of organizational forms (borders, transit areas, corridors), processes (lockdowns, digital tracking, quarantine) and behaviours (distancing, face covering) which has been advocated to control the pandemic to preserve both. In this process, life itself, the body, the human experience, have become the central objects of a spatial ordering (lockdown, quarantine, like during the great plague; Foucault, 1977) associated to (new) disciplinary and regulating technologies of power, depicted by Foucault (1977) as 'biopolitics', which marks the inscription of the biological into the political. Such a bio- power implies a progressive 'statization 'of the biological and the human experience (i.e. the bodies of individuals, their birth, health, age and death), allowing itself a rationality that is no longer linked to legal sovereignty, but that falls under economic liberalism).

Beyond this recent context, work transformations and new 'sites '(Schatzki, 2005) of work alter the structure of 'presence', 'silence 'and 'visibility 'of employees (de Vaujany \& Aroles, 2019; Leonardi \& Treem, 2020; Sewell \& Taskin, 2015) and supervisors (LeclercqVandelannoitte, 2020), and consequently affect the nature of the control of work practices 
(from supervision to more reporting, from technocratic to more social, peer- and selfcontrol): both horizontal relation- ships (with co-workers) and vertical relationships (with supervisors) are transformed. These new work practices imply a 'dispersal 'and 'distanciation '(Beyes \& Steyaert, 2012; Sewell \& Taskin, 2015) in the time and space of control (Bauman \& Lyon, 2013; Orlikowski, 1991) and raise singu- lar and often paradoxical challenges. On the one hand it entails collaborative forms of management control that extend beyond direct visual sight (Dambrin, 2004; Halford, 2005; Sewell, 2012), and on the other, forms of self-disciplining transformation in which autonomy becomes almost a synonym for neoliberal governance. Under the impress of both trends, surveillance has become an increasingly mobile, flexible, pervasive and unbounded synopticon (Bauman \& Lyon, 2013).

These new spatial practices, coupled to evolving IT uses, constitute a new kind of organizing of employees, placing them on an almost permanent 'front region '(Goffman, 1959) where issues of materiality, corporeity and temporality of control and surveillance through new work practices and work settings play a key role. For example, place still appears as a practical concern for mobile workers, who need to explicitly manage where and when they work on their specific work tasks, far from any supposed asynchronous hyperspace (e.g. Brown \& O'Hara, 2003; Hislop \& Axtell, 2009). The 'autonomy paradox ' (Mazmanian et al., 2013) even explains how the use of information technology triggers new constraints in the form of constant 'connectivity and accessibility 'norms beyond any autonomy in space and time (Mazmanian, Orlikowski, \& Yates, 2013, p. 1337; see also Wajcman \& Rose, 2011).

New work practices and recent work transformations enhance the complexity of situations to control and highlight the ambiguity of spaces, instruments, objects, artefacts, management systems and bodies (de Vaujany \& Aroles, 2019; Hansen \& Weiskopf, 2021; Koslowski, Linehan, \& Tietze, 2019; Leonardi \& Treem, 2020: Lorino, 2013; Miller, 2008, 
2009; Munro, 2016; Sewell \& Taskin, 2015; van Baarle, Dolmans, Bobelyn, \& Romme, 2021). For example, a 'caring mode of power 'as a subtle means of control increasingly marks modern organizations, in particular by instrumentally blurring the spatial boundaries between work and non-work activities in organizations (Leclercq- Vandelannoitte, 2021). The evolution of organizational control and surveillance through spatialities also points to the versatility of the uses of technologies in control and surveillance efforts (Brocklehurst, 2001; Orlikowski \& Scott, 2008); some research, for example, emphasizes a resurgence of ancient, bureaucratic forms of administration in new work settings, as managers seek to compensate for the distance, absence and lack of visibility of their subordinates (Halford, 2005; Orlikowski \& Scott, 2008; Sewell \& Taskin, 2015). Relatedly, there is an emerging interest in severance, de-coupling, going off-grid (Lovinck \& Rossiter, 2018; Strathern, 1996) and forms of existential resistance in which the widespread enthusiasm for connection, relationality and expansion is treated with suspicion. So, what of the glitches, of organization as unrelating, the imaginary of going it alone?

Time is a key aspect of most new virtual work design (Castells, 1996). Makerspaces and cow- orking spaces lives are enacted and punctuated by sensible events (e.g. periods of silence) that are constitutive of the place, its rhythms and modes of control (de Vaujany \& Aroles, 2019). Digital nomadism, as a non-place phenomenon, is largely temporal and self-managed as a (free) temporal- ity. Remote work and telework are enacted as key promises of autonomous management of one's time (likely at the end to enact new modes of control). What is our embodied experience of this apparently self-produced temporality? How do we sometimes reach a sense of shared temporalities in this 'new 'world of work? How do these new temporalities melt into digital semiosis and control us in turn? We see here particularly promising avenues for research for this third thematic block.

But strangely, if space and embodiment were part of the papers we received (and selected), we got very few contributions linking time (or temporality) to the issue of control 
and surveillance of (new) modes of organizing. Most management and organization studies researchers (in this special issue and beyond) link control to a target (the 'space 'of our activities) and a medium ('organizational space') which are central both in control and surveillance. More rarely, they investigate time and temporality as the central experience of control. This is for sure a missed opportunity to explore a politics of time in the context of new modes of organizing. Power obviously intervenes into the social organization of time, as shown by Foucault (1977)'s emphasis on the fundamental connection of power with practices of temporalization and timing (for example through the calculated and meticulous organization of time, like calendars or schedules that create a rhythmed, fragmented and optimized temporality - see also Zerubavel, 1985). The social organization of time results in the production of individualizing knowledge and is thus immanent to relations of power-knowledge, as well as control issues. Since the inception of the mechanical clock for example, we know that temporalization and its material modalities are a powerful tool of control and surveillance at work and of work (Thompson, 1967; de Vaujany, Mitev, Laniray, \& Vaast, 2014, p. 4). The first uses of mechanical clocks in Burgundy were in the context of several strikes in the Middle Ages. Vineyard workers quickly understood that they were also a way to control their work and to stand- ardize their daily activities (de Vaujany et al., 2014). 'Time penetrates the body and with it all the meticulous controls of power '(Foucault, 1977, p. 151).

However, if organization studies have long set out to demonstrate the importance of the 'time- space coupling 'underlying control and power relations (Foucault, 1977), time has been mostly understood through space (in line with the 'spatial turn 'in organization studies), thus contributing to a 'spatialization of time '(Portschy, 2020). Time always coexists 'within a wider organizational and institutional setting', explains Butler (1995, p. 936). Thus, in organization studies, and control- based research in particular, time is often conceptualized and organized in a space of which it is only the arrangement (Boullant, 
2003), such that temporalities, timing and chronologies are articulated in settlements, geographies, architectures, locations, movements and circulations. As empha- sized by Holt and Johnsen (2019, p. 1557), 'there has been a progressive forgetfulness of time in organization studies'. Although time and temporality have been a perennial subject for management and organization scholars (Hernes, Simpson, \& Söderlund, 2013; Lee \& Liebenau, 1999; Orlikowski \& Yates, 2002; Reinecke \& Ansari, 2017) and a central issue in social sciences (see Munn, 1992; Butler, 1995), 'the more time is being attended to in organization studies, the more it is concealed '(Holt \& Johnsen, 2019, p. 1557).

\section{New Organizational Forms and Possibilities for Autonomy}

The new technologies of platform capitalism and their algorithmic order are themselves a response to previous tactics of resistance to worker control, where new 'gig 'companies have adapted to the previous forms of worker solidarity and collective resistance by creating new techniques to divide and rule. Apps like Uber work by individualizing and isolating the workforce and engaging the user and their customer in its system of surveillance, meaning the management function is no longer performed by a separate class of organizational bureaucrats (Marglin, 1976). Algorithms and Al are increasingly constituting a system of coordination and control and surveillance based upon intensive networks of data capture (also see the notion of 'algoactivism'; Kellogg, Valentine, \& Christin, 2020). Entrepreneurs, freelancers and digital nomads are themselves becoming integrated within business platforms that employ an unobtrusive network of increasingly intense surveillance of our everyday activities. The recent rise of remote work with the pandemic has reinforced this trend. Moreover, many of those who resist may no longer be from a distinct, politicized opposition, where the uptake of platform technology has fostered the imaginaries of a cadre of activists working from within these same organizations (Skoglund \& Böhm, 2020). 
Interestingly, contemporary observers of digital work defend a symmetric thesis. Beyond Al and platforms, an army of digital workers would be hidden (Casilli, 2019). This mother selling products she bought on the French 'Bon Coin', this guy rating a travel on Tripadvisor, these students clicking on images to help an Al tool recognize them or, more simply, all the people delivering items we bought online at our door. Beyond the hope of robots simplifying our lives, making it possible for us to focus on leisure (as intellectual elevation), digitality may embody a new world of slavery for some if not all of us.

Obviously, free labour and digital labour are parts of the new world of work, its precarity and its rising inequalities. Most of all, these processes behind $\mathrm{Al}$ and platforms feed new forms of self-control based on the various apps connected to the so-called 'ecosystem'. Everybody rates and reviews everybody, continuously within the platform synopticon. Yet despite all this invasive organizational presence in the ordinary everyday lives of workers, the technological spread is also fostering glimpses of radically different forms of work and modes of organizing. It is not such a leap to move from freelancing, flexwork, remote work and cowork to a much more open and ungovernable form of digital nomadism currently going by monikers such as Bring Your Own Device (BYOD), Do It Yourself (DIY), Do It Together (DIT), holacracy, neocraftmanship, maker movements, open source and other open modes of peer-based organization and organizing (Aroles et al., 2019; Bohas, Fabbri, Laniray, \& de Vaujany, 2018; Kingma, 2019). Autonomy and even emancipation are often their key promises. Let's build a world beyond organizations, beyond any walls, any constraints and any hierarchies! Work whenever you want, with whom you want, where you want, and with the tools you want! Just the output will matter for 'us'. . . All these sentences could be the slogans/motto of a new world of work that might appear almost sui generis to what has been critiqued as the global elevation of a corporate elite buoyed by the relentless ordering of a pliant precariat. 
Politically and socially, as well as economically, this situation is destabilizing the ideological categories typically associated with control and surveillance. On a standard reading, control and surveillance were conceived through representational forms grounded in ideology and spread through symbolic forms of domination: they were forces through which distinct and potentially errant individuals were organized into a compliant unity by using concepts (identity, role, office, promise, contract, duty) backed by discourses (jurisprudence, psychoanalysis, neoclassical economics). Control and surveillance were done to things, from the outside so to speak. Now, with the irresistible spread of technology into all sentient and non-sentient life, they have become part of the life force of self-generating, self-organizing things themselves: they come as much from within as without and are constitutive of paradoxical more than dialectical phenomena. Our world of work, and beyond that, our organizing processes, do not result in antagonist forces visibly balanced by a third-force and third-party (management?). These days, users of digital technologies appear to remain relatively unconcerned with surveillance, accepting the trade-off of greater usability for decreased control (Best, 2010). Novel types of control find increasing legitimacy among the con- trolled people, who may cooperate willingly with their controllers, in a relation that raises new tensions between technology and morality (Bauman \& Lyon, 2013). The pandemic may strengthen this deep legitimation process of self-surveillance.

Daudigeos, Edwards, Jaumier, Pasquier and Picard (2021) have shown how recent corporate policies of 'neo-participation 'provide an illusory sense of worker participation which down- plays internal conflict and allows little opportunity for worker selfdetermination. People increasingly provide data (seemingly) happily and voluntarily, such as through social media, thus inverting the roles of 'watcher 'and 'watched '(Galič, Timan, \& Koops, 2016). The meaning and norm of 'sharing 'has markedly shifted over the past decade, though buttons on Facebook such as 'share', that are designed and used in ways 
that constitute them as a new social norm and social value (van Dijck, 2013). These practices imply that visibility is now chosen, and they make power relations in society more diffuse (Lyon, 2015) while simultaneously transforming the classic principle of panopticism where the "algorithmic gaze 'does not merely replace human observation in organisational settings; it also replaces human decision-making '(Newlands, this issue, p. 14).

These tensions are generative of our experience of the world. They remain dyschronic, conflict- ing and sometimes painful, and as Resch et al. (this issue) argue, these experiences should not be too readily associated with a lack of autonomy. In the stead of an easily discerned, hegemonic oppressive 'big other '(a form that Zuboff perhaps too quickly invokes to describe the origin point of systems surveillance and control), Resch et al. notice a far more elusive, affective form of surveillance and control to which workers are willingly enjoined. This communal other is an atmospheric setting of intrinsic motivation, self-management and collective intellectual promise constituted through fantasies of purpose, possibility and belonging. Surveillance and control were intrinsic to the working of such collaborative communities, but being affective they were not easily settled in traditional managerial structures of command and control. Rather they became manifest in a range of ambivalent subjectivities that were at one and the same time joyously contributing to a community to which they were continually exposed: delight lived alongside gloom, motivation alongside frustration, pleasantries alongside the stressful.

\section{Conclusion}

In the context of these new emerging forms, how can we frame and conceptualize the autonomy vs. control paradox being experienced in the contemporary world of work? New forms of control have become increasingly unmoored from the panoptic architecture of surveillance, where flexible and mobile technologies and work practices promote the circulation of flows of human and social capital. The neoliberal techniques of government 
for the promotion of competition and entrepreneur- ship are not only government policy (Fleming, 2014; Munro, 2012), they are being increasingly built into the technological interfaces, platforms and apps by means of which we interact at work. How are communication, platforms and the sensing of time and space constitutive of new relationships between autonomy and control? As a way both to end and open this introduction, we want to suggest a paradoxical answer here. This new world of work generates a new tension between autonomy and control, where technologies are promoting increased flexibility in terms of the time and space of work, at the same time as increasing control and surveillance. They are increasingly embedded in our everyday interactions, in our social media and Internet of things, where the feed- back received is processed by algorithms to generate further interactions, which are designed to fit in with corporate aims (see Alaimo \& Kallinikos, 2020).

In these turbulent times and societies (a fortiori in the current pandemic context; Leonardi, 2021), marked by space-time compression enabled by the digital and increasingly blurred boundaries (between work and life, professional and private spheres), time and space increasingly penetrate one another. Empirical evidence even suggests that spaces, distances, boundaries are increasingly governed, and somewhat annihilated, by time and dyschronies. From the late 1990s, we moved into a multi-polar, network-based, connected world. More than ever, temporality is not felt as something shared. Our world becomes largely dyschronic, i.e. made of multiple conflicts of temporalities in a present that is not shared anymore (Alter, 2000). Temporal orientations bump into each other and are not directed nor synthetized by anything. Control does not overhang any- thing. It is part of our paradoxical (and sometimes painful) relationship to the world. In this new world of work (especially during the pandemic context marked by the rapid generalization of tel- ework), conflicting and competing demands and values have to bear each other: for example, the discourse of industrial production increasingly meets the discourse of household 
production (see Tietze \& Musson, 2005; Koslowski et al., 2019). Similarly, the engagement with new ways of working increasingly requires workers to set up workspaces for both personal productivity and sociality (cf. Brown \& O'Hara, 2003).

In this context, we hanker both for autonomy and control. We activate both control and autonomy processes. The here and now of our desire for autonomy bumps into decentred processes of control located in various pasts, presents and futures. We are crossed by multiple contradictory flows that constitute a world that is just shared (provisionally) at its borders. We just share some frontiers and liminalities in the new worlds of work (Starbuck coffees, our sofa soon occupied by our daughter to watch TV, a seat for a day in a coworking space, a session on Zoom, a meeting with other gamers on Discord, a time of play on Snapchat. . .). We cross them but we do not occupy them any more. Digitality is the very large enabler and mediation of these dyschronies. And the Covid-19 crisis has made more visible and more present this process of 'liminalization'. Work is not a grounded time-space unity any more, a heavy production tool or IT artifacts. It is an ephemeral and precarious connective activity that can take place everywhere, every time. A mnesic trace potentially meaningful and subject of surveillance processes fed by ourselves. Most of all, it is not fully 'work 'any more.

With the blurring of the frontier between work and leisure (as entertainment), private and professional spheres, intimate and public realms (Aroles et al., 2019; Golden \& Geisler, 2007; Koslowski et al., 2019), we all invest in new ways of living at large. We work without always knowing we work (we work for free) in our addictions to social media capturing our attention and monitoring our behaviours and interactions, in gamified spaces of work making us produce things with fun (Leclercq-Vandelannoitte, 2021), in traditional workspaces through 'homemaking 'activities (Wilhoit Larson, 2020) or at home while taking care of our children and paying for our own work environment (Eddleston \& Mulki, 2017; Hardill \& Green, 2003). We avoid the long transitions in trains, buses and cars and 
exchange them for a world that could in the end locate us continuously in a transitional time. Always in the middle of two things (e.g. our children and our work), we drift from one activity to another. We all want to believe in the promises of management about a better world at hand if we just buy this new product or new service. We cope the best we can with our world by paradoxically drawing on communities in hyper-individualized environments (see Resch et al., 2021, in this issue). We commodify and managerialize identity emancipation, which strangely produces new forms of queer control in the context of a new world of work, which is expected to be freed from any forms of control (see Burchiellaro, 2021, in this issue). We design new open spaces and new work configurations, which in the end assemble with new forms of governmentality in paradoxical ways (see Picard et al., 2021, in this issue). The notion of 'pay- ing to work', as the basis of coworking's political economy (see de Peuter et al., 2017), for example, highlights the inherent 'social and political ambivalence 'of this new world of work. The ways in which new platforms, apps and mobile surveillance technologies are unobtrusively embedded within both our work and non-work social interactions confront us with stark problems concerning our exercise of autonomy, democratic decision-making and the creation of any time and space in which to resist power.

These dyschronies, which translate an unprecedented break in the traditional time-space unity of organizing, reveal the significance of deepening our knowledge of time and temporality as a crucial political component of organizing, working, controlling, resisting and self-disciplining (as a way to govern the self and others; Foucault, 1982-1983). More than ever before, it may be time to reinvigorate our interest in time, and (re)open organization studies to a (new) 'temporal turn 'towards a politics of time, through a possible 'temporalization of space', beyond the traditional 'spatialization of time '(Foucault, 1977; Portschy, 2020) observed so far in organization studies. This could help us better grasp the tensions between the two essential dimensions of the human experience, space 
and time, and their constitutive role in the autonomy-control paradox experienced in the new world of work.

In that regard, the research presented in this special issue shows that these new forms of work permit numerous opportunities for workers and managers to develop creative tactics of resistance to the emerging world of algorithmic surveillance and meaningful modes of organizing (see Hafermalz, 2021 and Newlands, 2021, in this issue). Autonomy and control will always be inter- woven in our ways of working and living. Let's do our best to be the patient gardener of their generative tensions for our organizations and our societies.

\section{Acknowledgements}

We are grateful for the editorial support of Daniel Hjorth in developing our manuscript. We also want to thank the participants of the ST on 'Control, Materiality and Practices 'at EGOS 2016 and our co-convenors Emmanuelle Vaast and Andrew Pickering for inspiring the subject of this Special Issue.

\section{References}

Ahrens, Thomas, \& Mollona, Massimiliano (2007). Organisational control as cultural practice: A shop floor ethnography of a Sheffield steel mill. Accounting, Organizations and Society, 32, 305-331.

Alaimo, Cristina, \& Kallinikos, Janis (2020). Managing by data: Algorithmic categories and organizing. Organization Studies. doi:10.1177/0170840620934062.

Alter, Norbert (2000). Logique de l'innovation ordinaire. Paris: Presses Universitaires de France.

Alvesson, Mats, \& Kärreman, Dan (2004). Interfaces of control: Technocratic and socio ideological control in a global management consultancy firm. Accounting, Organizations and Society, 29, 423-444. 
Aroles, Jeremy, Mitev, Nathalie, \& de Vaujany, François-Xavier (2019). Mapping themes in the study of new work practices. New Technology, Work and Employment, 34, 285-299. Bailey, Diane E., \& Kurland, Nancy B. (2002). A review of telework research: Findings, new directions, and lessons for the study of modern work. Journal of Organizational Behavior, 23, 383-400.

Ball, Kirstie (2005). Organization, surveillance and the body: Towards a politics of resistance. Organization, 12, 89-108.

Barker, Timothy S. (2012). Time and the digital: Connecting technology, aesthetics, and a process philosophy of time. Dublin: Dartmouth Publishing Group.

Barker, Timothy S. (2018). Against transmission: Media philosophy and the engineering of time. London: Bloomsbury Publishing.

Baschet, J. (2008). L'iconographie médiévale. Paris: Gallimard.

Baskerville, Richard L., Myers, Michael D., \& Yoo, Youngjin (2020). Digital first: The ontological reversal and new challenges for information systems research. MIS Quarterly, 44, 509-523.

Bauman, Zygmunt, \& Lyon, David (2013). Liquid surveillance: A conversation. New York: John Wiley and Sons. Braverman, Harry (1974). Labor and monopoly capital. New York: Monthly Review Press.

Best, Kirsty (2010). Living in the control society: Surveillance, users and digital screen technologies. International Journal of Cultural Studies, 13, 5-24.

Beyes, Timon, \& Holt, Robin (2020). The topographical imagination: Space and organization theory. Organization Theory. https://doi.org/10.1177/2631787720913880 Beyes, Timon, Holt, Robin, \& Pias, Claus (2019). By means of which: Media, technology and organization. In Timon Beyes, Robin Holt, \& Claus Pias (Eds.), The Oxford handbook of media, technology and organization studies (pp. 498-514). Oxford: Oxford University Press. 
Beyes, Timon, \& Steyaert, Chris (2012). Spacing organization: Non-representational theorizing and the spatial turn in organizational research. Organization, 19, 45-61. Bohas, Amélie, Fabbri, Julie, Laniray, Pierre, \& de Vaujany, François-Xavier (2018). Hybridations salariat- entrepreneuriat et nouvelles pratiques de travail : des slashers à l'entrepreneuriat- alterné. Technologie et innovation, 18(1), 1-19.

Boullant, François (2003). Michel Foucault, penseur de l'espace. http://www.univlille3.fr/set/sem/boullant.html.

Brivot, Marion, \& Gendron, Yves (2011). Beyond panopticism: On the ramifications of surveillance in a contemporary professional setting. Accounting, Organizations and Society, 36(3), 135-155.

Brocklehurst, Michael (2001). Power, identity and new technology homework: Implications for new 'forms 'of organizing. Organization Studies, 22, 445-466.

Brown, Barry, \& O'Hara, Kenton (2003). Place as a practical concern of mobile workers. Environment and Planning, 35, 1565-1587.

Brunton, Finn, \& Nissenbaum, Helen (2015). Obfuscation: A user's guide for privacy and protest. Cambridge, MA: MIT Press.

Burchiellaro, Olimpia (2021). Queering control and inclusion in the contemporary organization: On 'LGBT- friendly control 'and the reproduction of (queer) value. Organization Studies, 42

Burnham, James (1941). The managerial revolution. London: Putnam \& Co..

Butler, Richard (1995). Time in organizations: Its experience, explanations and effects. Organization Studies, 16, 925-950.

Calvo, Rafael A., Deterding, Sebastian, \& Ryan, Richard M. (2020). Health surveillance during covid-19 pandemic. BMJ, 369, m1373.

Casilli, Antonio (2019). En attendant les robots-Enquête sur le travail du clic. Paris: Le Seuil. 
Castells, Manuel (1996). The rise of the network society: the information age, economy, society and culture, vol. 1. Oxford: Blackwell.

Clegg, Stewart, \& Dunkerley, David (1980). Organization, class and control. London: Routledge. Courpasson, David (2000). Managerial strategies of domination. Power in soft bureaucracies. Organization Studies, 21, 141-161.

Dale, Karen (2005). Building a social materiality: Spatial and embodied politics in organizational control. Organization, 12, 649-678.

Dale, Karen, \& Burrell, Gibson (2008). The spaces of organisation and the organisation of space: Power, identity and materiality at work. Basingstoke, UK: Palgrave Macmillan.

Dambrin, Claire (2004). How does telework influence the manager-employee relationship? International Journal of Human Resources Development and Management, 4, 358-374. Daudigeos, Thibault, Edwards, Tim, Jaumier, Stéphane, Pasquier, Vincent, \& Picard, Hélène (2021). Elusive domination and the fate of critique in neo-participative management: A French pragmatist approach. Organization Studies, 42, 453-471.

De Molli, Frederica, Mengis, Jeanne, \& van Marrewijk, Alfons (2020). The aestheticization of hybrid space: The atmosphere of the Locarno Film Festival. Organization Studies, 41, $1491-1512$.

de Peuter, Greig, Cohen, Nicole S., \& Saraco, Francesca (2017). The ambivalence of coworking: On the politics of an emerging work practice. European Journal of Cultural Studies, 20, 687-706.

de Vaujany, François-Xavier (2010). A new perspective on the genealogy of collective action through the history of religious organizations. Management and Organizational History, 5(1), 65-78.

de Vaujany, François-Xavier, \& Aroles, Jeremy (2019). Nothing happened, something happened: Silence in a makerspace. Management Learning, 50, 208-225. de Vaujany, François-Xavier, \& Mitev, Nathalie (2017). The post-Macy paradox, 
information management and organizing: Good intentions and a road to hell? Culture and Organization, 21, 379-407.

de Vaujany, François-Xavier, Mitev, Nathalie, Laniray, Pierre, \& Vaast, Emmanuelle (2014). Introduction: time and materiality: What is at stake in the materialization of time and time as a materialization? In François-Xavier de Vaujany, Nathalie Mitev, Pierre Laniray, \& Emmanuelle Vaast (Eds.), Materiality and time (pp. 1-13). London: Palgrave Macmillan.

de Vaujany, François-Xavier, \& Vaast, Emmanuelle (2016). Matters of visuality in legitimation practices: Dual iconographies in a meeting room. Organization, 23, 763-790. Deetz, Stanley (1992). Disciplinary power in the modern corporation: Discursive practice and conflict suppression. In Mats Alvesson \& Hugh Willmott (Eds.), Critical management studies (pp. 21-52). London: SAGE Publications.

Delbridge, Rick, \& Sallaz, Jeffrey J. (2015). Work: Four worlds and ways of seeing. Organization Studies, 36, 1449-1462.

Deleuze, Gilles (1992). Postscript on the Societies of Control. October, 59, 3-7. Eddleston, Kimberly A., \& Mulki, Jay (2017). Toward understanding remote workers ' management of work- family boundaries: The complexity of workplace embeddedness. Group and Organization Management, 42, 346-387.

Edwards, Richard (1979). Contested terrain: The transformation of the workplace in the twentieth century. New York: Basic Books.

Flamholtz, Eric (1996). Effective organizational control: A framework, applications, and implications. European Management Journal, 14, 596-611.

Fleming, Peter (2014). Review Article: When 'life itself 'goes to work: Reviewing shifts in organizational life through the lens of biopower. Human Relations, 67, 875-901. 
Flyverbom, Mikkel, Deibert, Ronald, \& Matten, Dirk (2019). The governance of digital technology, big data, and the internet: New roles and responsibilities for business.

Business and Society, 58, 3-19.

Foucault, Michel (1977). Discipline and punish: The birth of the prison. London: Allen \& Lane.

Foucault, Michel (1982) The subject and power. Critical Inquiry, 8, 777-795.

Foucault, Michel (1982-1983/2010). The Government of Self and Others: Lectures at the Collège de France 1982-1983, edited by Arnold I. Davidson. New York: Palgrave Macmillan.

Friis Nielsen, Martin (2021). Consuming memory: Towards a conceptualization of social media platforms as organizational technologies of consumption. Frederiksberg:

Copenhagen Business School (PhD Series, No. 04.2021).

Galič, Maša, Timan, Tjerk, \& Koops, Bert-Jaap (2016). Bentham, Deleuze and beyond: An overview of surveillance theories from the Panopticon of participation. Philosophy and Technology, 30, 9-37.

Gandini, Alessandro (2015). The rise of coworking spaces: A literature review. Ephemera - Theory and Politics in Organization, 15(1), 193-205.

Giddens, Anthony (1985). Time, space and regionalisation. In Social relations and spatial structures (pp. 265-295). London: Palgrave Macmillan.

Goffman, Erving (1959). The presentation of self in everyday life. New York: Doubleday Anchor Books.

Golden, Annis G., \& Geisler, Cherryl (2007). Work-life boundary management and the personal digital assistant. Human Relations, 60, 519-551.

Gonsalves, Leroy (2020). From face time to flex time: The role of physical space in worker temporal flexibility. Administrative Science Quarterly, 65, 1058-1091.

Halford, Susan (2005). Hybrid workspace: Re-spatialisations of work, organisation and 
management. New Technology, Work and Employment, 20, 19-33.

Hafermalz, Ella (2021). Out of the panopticon and into exile. Organization Studies, 42, Hafermalz, Ella, \& Riemer, Kai (2020). Interpersonal connectivity work: Being there with and for geographically distant others. Organization Studies, 41, 1627-1648.

Hansen, Mark B.N. (2006). Bodies in code. New York: Routledge.

Hansen, Hans K., \& Weiskopf Richard (2021). From universalizing transparency to the interplay of transparency matrices: Critical insights from the emerging social credit system in China. Organization Studies, 42, 109-128.

Hardill, Irene, \& Green, Anne (2003). Remote working: Altering the spatial contours of work and home in the new economy. New Technology, Work and Employment, 18, 212222.

Hardt, Michael, \& Negri, Antonio (2009). Commonwealth. Boston, MA: Harvard University Press.

Hardy, Cynthia, \& Thomas, Robyn (2015). Discourse in a material world. Journal of Management Studies, 52, 680-696.

Helmond, Anne (2015). The platformization of the web: Making web data platform ready. Social Media + Society. https://doi.org/10.1177/2056305115603080

Heims, Steve J. (1991). The Cybernetics Group 1946-1953: Constructing a social science for postwar America. Boston, MA: MIT Press.

Hernes, Tor, Simpson, Barbara, \& Söderlund, Jonas (2013). Managing and temporality. Scandinavian Journal of Management, 29(1), 1-6.

Hislop, Donal, \& Axtell, Caroline (2009). To infinity and beyond? Workspace and the multilocation worker. New Technology, Work and Employment, 24, 60-75.

Holt, Robin, \& Johnsen, Rasmusen (2019). Time and organization studies. Organization Studies, 40, 1557-1572.

Idhe, Don (2009). Post-phenomenology and technoscience. New York: SUNY Press. 
Jørgensen, Lydia, \& Holt, Robin (2019). Organization, atmosphere, and digital technologies: Designing sen- sory order. Organization, 26, 673-695.

Kaye, Joel (2014). A history of balance, 1250-1375: The emergence of a new model of equilibrium and its impact on thought. London: Cambridge University Press.

Kellogg, Katherine C., Valentine, Melissa A., \& Christin, Angèle (2020). Algorithms at work: The new con- tested terrain of control. Academy of Management Annals, 14(1), 366-410. Kieser, Alfred (1989). Organizational, institutional, and societal evolution: Medieval craft guilds and the genesis of formal organizations. Administrative Science Quarterly, 34, 540564.

Kingma, Sytze (2019). New ways of working (NWW): Workspace and cultural change in virtualizing organi- zations. Culture and Organization, 25(5), 383-406.

Kline, Ronald R. (2006). Cybernetics, management science, and technology policy: The emergence of 'infor- mation technology 'as a keyword, 1948-1985. Technology and Culture, 47, 513-535.

Kolb, Dar G., Dery, Kristine, Huysman, Marleen, \& Metiu, Anca (2020). Connectivity in and around organi- zations: Waves, tensions and trade-offs. Organization Studies, 41, 15891599.

Koslowski, Nora R., Linehan, Carol, \& Tietze, Susanne (2019). When is a bed not a bed? Exploring the interplay of the material and virtual in negotiating home-work boundaries. Culture and Organization, 25, 159-177.

Kurland, Nancy B., \& Egan, Terri D. (1999). Telecommuting: Justice and control in the virtual organization. Organization Science, 10, 500-513.

Leclercq-Vandelannoitte, Aurélie, Isaac, Henri, \& Kalika, Michel (2014). Mobile information systems and organisational control: Beyond the panopticon metaphor? European Journal of Information Systems, 23, 543-557. 
Leclercq-Vandelannoitte, Aurélie (2020). Seeing to be seen: The manager's political economy of visibility in new ways of working, European Management Journal, forthcoming. Leclercq-Vandelannoitte, Aurélie (2021). The new paternalism? The workplace as a place to work—and to live. Organization, forthcoming.

Leclercq-Vandelannoitte, Aurélie, \& Aroles, Jeremy (2020). Does the end justify the means? Information systems and control society in the age of pandemics. European Journal of Information Systems. doi: 10.1080/0960085X.2020.1820912.

Lee, Heejin, \& Liebenau, Jonathan (1999). Time in organizational studies: Towards a new research direction. Organization Studies, 20, 1035-1058.

Leonardi, Paul M., \& Treem, Jeffrey W. (2020). Behavioral visibility: A new paradigm for organization studies in the age of digitization, digitalization, and datafication. Organization Studies, 41, 1601-1625.

Leonardi, Paul M. (2021). Covid-19 and the new technologies of organizing: Digital exhaust, digital footprints, and artificial intelligence in the wake of remote work. Journal of Management Studies, 58, 249-253.

Lorino, Philippe (2013). Management systems as organizational 'architextures'. In François-Xavier de Vaujany \& Nathalie Mitev (Eds.), Materiality and space: Organization, artefacts and practices (pp. 62-95). New York: Palgrave Macmillan.

Lovink, Geert, \& Rossiter, Ned (2018). Organization in platform capitalism. Posthuman Glossary, 306-308. Lyon, David (2002). Surveillance studies: Understanding visibility, mobility and the phenetic fix. Surveillance and Society, 1, 1-7. Lyon, David (2015). Surveillance after snowden. London: John Wiley \& Sons. MacKay, Brad, \& Munro, lain (2012). Information warfare and new organizational landscapes: An inquiry into the ExxonMobil-Greenpeace dispute over climate change. Organization Studies, 33, 1507-1536. 
Marglin, Stephen A. (1976). What do bosses do? The origins and functions of hierarchy in capitalist production. In André Gorz (Ed.), The division of labour: The labour process and class struggles in modern capitalism (pp. 13-54). Brighton, UK: Harvester Press.

Marx, Karl $(1909,1976)$. Capital: A critique of political economy. Volume I: The process of capitalist production. Trans. by Samuel Moore \& Edward Aveling. Revised and amplified by Ernest Untermann. Chicago: Charles H. Kerr \& Co.

Mazmanian, Melissa, Orlikowski, Wanda J., \& Yates, JoAnne (2013). The autonomy paradox: The implications of mobile email devices for knowledge professionals.

Organization Science, 24, 1337-1357.

Miller, Daniel (2008). The comfort of things. Cambridge: Polity.

Miller, Daniel (2009). Stuff. Cambridge: Polity.

Mintzberg, Henry (1983). Structure in fives: Designing effective organizations. Englewood Cliffs, NJ: Prentice-Hall.

Monteiro, Eric (2018). Reflections on digital innovation. Information and Organization, 28, 101-103. Morozov, Evgeny (2019). Digital socialism? The calculation debate in the age of big data. New Left Review, 116/117, 33-67.

Munn, Nancy D. (1992). The cultural anthropology of time: A critical essay. Annual Review of Anthropology, 21(1), 93-123.

Munro, lain (2000). Non-disciplinary power and the network society. Organization, 7, 679695.

Munro, lain (2012). The management of circulations: Biopolitical variations after Foucault. International Journal of Management Reviews, 14, 345-362.

Munro, lain (2016). Organizational resistance as a vector of deterritorialization: The case of WikiLeaks and secrecy havens. Organization, 23, 567-587.

Munro, lain, \& Jordan, Silvia (2013). 'Living Space 'at the Edinburgh Festival Fringe:

Spatial tactics and the politics of smooth space. Human Relations, 66, 1497-1525. 
Newlands, Gemma (2021). Algorithmic surveillance in the gig economy: The organisation of work through Lefebvrian conceived space. Organization Studies, 42, Orlikowski, Wanda J. (1991). Integrated information environment or matrix of control? The contradictory implications of information technology. Management and Information Technology, 1, 9-42.

Orlikowski, Wanda J., \& Scott, Susan V. (2008). Sociomateriality: Challenging the separation of technology, work and organization. Academy of Management Annals, 2(1), 433-474.

Orlikowski, Wanda J., \& Yates, JoAnne (2002). It's about time: Temporal structuring in organizations. Organization Science, 13, 684-700.

Pavlou, Paul A. (2011). State of the information privacy literature: Where are we now and where should we go? MIS Quarterly, 35, 977-988.

Picard, Claire-France, Durocher, Sylvain, \& Gendron, Yves (2021). Office design, neoliberal governmentality and professional service firms. Organization Studies, 42 Portschy, Jürgen (2020). Times of power, knowledge and critique in the work of Foucault. Time and Society, 29(2), 392-419.

Quatronne, Paolo (2019). The forgotten history of accounting words. FM magazine, December. https://www. fm-magazine.com/issues/2019/dec/history-of-accountingwords.html

Quine, Willard V. (1976). The ways of paradox and other essays. London: Harvard University Press.

Raffnsøe, Sverre, Mennicken, Andrea, \& Miller, Peter (2019) The Foucault effect in organization studies. Organization Studies, 40, 155-182.

Raley, Rita (2013). Dataveillance and countervailance. In Lisa Gitelman (Ed.), 'Raw data ' is an oxymoron (pp. 121-146). Cambridge, MA: MIT Press.

Reckwitz, Andreas (2016). How senses organize the social. In Michael Jonas \& Beate 
Littig (Eds.), Praxeological political analysis (pp. 56-66). London: Routledge.

Reinecke, Juliane, \& Ansari, Shaz (2017). Time, temporality and process studies. In Ann Langley \&

Haridimos Tsoukas (Eds.), The Sage handbook of process organization studies (pp. 402416). London: SAGE Publications.

Resch, Bernhardt, Hoyer, Patrizia, \& Steyaert, Chris (2021). Affective control in new collaborative work:

Communal fantasies of purpose, growth and belonging. Organization Studies, 42

Robb, Fenton F. (1984). Cybernetics in management thinking. Systems Research, 1(1), 523.

Rowe, Frantz, Ngwenyama, Ojelanki, \& Richet, Jean-Loup (2020). Contact-tracing apps and alienation in the age of COVID-19. European Journal of Information Systems, 29, $545-562$.

Sage, Daniel, Vitry, Chloé, \& Dainty, Andrew (2020). Exploring the organizational proliferation of new technologies: An affective actor-network theory. Organization Studies, $41,345-363$.

Schatzki, Theodore R. (2005). Peripheral vision: The sites of organizations. Organization studies, 26, 465-484.

Sewell, Graham (1998). The discipline of teams: The control of team-based industrial work through electronic and peer surveillance. Administrative Science Quarterly, 43, 397-428. Sewell, Graham (2012). Employees, organizations and surveillance. In Kirstie Ball, Kevin D. Haggerty, \& David Lyon (Eds.), The handbook of surveillance studies (pp. 303-312). London: Routledge.

Sewell, Graham, \& Taskin, Laurent (2015). Out of sight, out of mind in a new world of work? Autonomy, control, and spatiotemporal scaling in telework. Organization Studies, 36, 1507-1529. 
Skoglund, Annika, \& Böhm, Steffen (2020). Prefigurative partaking: Employees ' environmental activism in an energy utility. Organization Studies, 41, 1257-1283.

Srnicek, Nick (2017). Platform capitalism. Cambridge: Polity Press.

Steinberg, Marc (2019). The platform economy: How Japan transformed the consumer internet. Minneapolis: University of Minnesota Press.

Strathern, Marilyn (1996). Cutting the network. Journal of the Royal Anthropological Institute, 2(3), 517-535.

Sveningsson, Stefan, \& Alvesson, Mats (2003). Managing managerial identities:

Organizational fragmentation, discourse and identity struggle. Human Relations, 56, 11631193.

Tietze, Susanne, \& Musson, Gill (2005). Recasting the home-work relationship: A case of mutual adjustment? Organization Studies, 26, 1331-1352.

Thompson, Edward P. (1967). Time, work-discipline, and industrial capitalism. Past and Present, 38, 56-97.

Umpleby, Stuart A. (2005). A history of the cybernetics movement in the United States. Journal of the Washington Academy of Sciences, 54-66.

Vaidhyanathan, Siva (2018). Antisocial media: How Facebook disconnects us and undermines democracy. Oxford: Oxford University Press.

van Baarle, Steven, Dolmans, Sharon A., Bobelyn, Annelies S., \& Romme, George L. (2021). Beyond command and control: Tensions arising from empowerment initiatives. Organization Studies, 42, 531-553.

Van Dijck, Jose (2013). The culture of connectivity: Critical history of social media. Oxford: Oxford University Press.

Wajcman, Judy, \& Rose, Emily (2011). Constant connectivity: Rethinking interruptions at work. Organization Studies, 32, 941-961.

Wiesenfeld, Batia M., Ragurham, Sumita, \& Garud, Raghu (1999). Managers in a virtual 
context: The experience of self-threat and its effects on virtual work organization. In Cary

L. Cooper \& Denise M. Rousseau (Eds.), Trends in organizational behaviour, Vol. 6, Chichester, UK: Wiley.

Wilhoit Larson, Elizabeth (2020). Creating home at work: Humanistic geography and placemaking in organizations. Culture and Organization, 1-19, https://doi.org/10.1080/14759551.2020.1861453.

Wilson, Jeanne, O'Leary, Michael B., Metiu, Anca, \& Jett, Quintus (2008). Perceived proximity in virtual work: Explaining the paradox of far-but-close. Organization Studies, 29, 979-1002.

Zakir, Jasmine, Seymour, Tom, \& Berg, Kristi (2015). Big data analytics. Issues in Information Systems, 16(2).

Zerubavel, Eviatar (1985). Hidden rhythms: Schedules and calendars in social life. Berkeley, CA: University of California Press.

Zuboff, Shoshana (2015). Big other: Surveillance capitalism and the prospects of an information civilization. Journal of Information Technology, 30, 75-89.

Zuboff, Shoshana (2019). The age of surveillance capitalism: The fight for a human future at the new frontier of power. London: Profile Books. 